\title{
Assessoria pedagógica ao docente universitário: Uma carreira em construção
}

\author{
Ligia Bueno Zangali Carrasco ${ }^{1}$ \\ Amanda Rezende Costa Xavier \\ Maria Antonia Ramos de Azevedo \\ Universidade Estadual Paulista "Julio de Mesquita Filho" - UNESP, Rio Claro-SP, Brasil
}

\section{Resumo}

Esse artigo empreende estudo teórico sobre o profissional que trabalha com a formação pedagógica do professor universitário aqui denominado assessor pedagógico universitário. Busca tornar a reflexão pedagógica na universidade uma prática, desenvolvendo o olhar sobre a docência como um exercício profissional. Neste sentido, este estudo objetiva, também, abrir a possibilidade de reflexão e discussão acerca da formação pedagógica do docente universitário, sob a ótica do profissional responsável por desencadear os processos formativos junto aos docentes, ou seja, sob a ótica do assessor pedagógico. Aprofundar os conhecimentos sobre este profissional pode ser um caminho para se rever uma enraizada cultura institucional, pautada em um ensino instrumentalizado e de transmissão que ainda resiste no interior da universidade.

Palavras-chave: Assessoria pedagógica universitária, identidade profissional, formação

\section{Abstract: Pedagogical advice to university professors: A career under construction}

This article undertakes a theoretical study about the professional that works with the pedagogical training of the university professor here called university pedagogical advisor. Search to make a reflection in the university a practice, developing the look on teaching as a professional exercise. In this sense, this study also aims to open the possibility of reflection and discussion about the university professor's pedagogical formation, from the view of the professional responsible for initiating the formative processes with the professors, that is, from the view of pedagogical advisor. Deepening the knowledge about this professional can be a way to review a rooted institutional culture, based on an instrumentalized and transmission teaching that still resists inside the university. Keywords: University pedagogical advisor, professional identity, training

\section{Resumen: Asesoría pedagógica al docente universitario: Una carrera en construcción}

Este artículo emprende estudio teórico sobre el profesional que trabaja con la formación pedagógica del profesor universitario aquí denominado asesor pedagógico universitario. Búsqueda de una reflexión pedagógica en la universidad una práctica, desarrollando la mirada sobre la docencia como un ejercicio profesional. En este sentido, este estudio objetiva, también, abrir la posibilidad de reflexión y discusión acerca de la formación pedagógica del docente universitario, bajo la óptica del profesional responsable por desencadenar los procesos formativos junto a los docentes, o sea, bajo la óptica del asesor pedagógico. La profundización de los conocimientos sobre este profesional puede ser un camino para revisar una enraizada cultura institucional, pautada en una enseñanza instrumentalizada y de transmisión que aún resiste en el interior de la universidad.

Palabras clave: Asesor pedagógico universitario, identidad profesional, formación

\footnotetext{
${ }^{1}$ Endereço para correspondência: Rua 5, 3700, Bloco 3, apto 31, Vila Operária, 13504-114, Rio Claro, SP. E-mail: li_carrasco@yahoo.com.br
} 
A discussão sobre o assessoramento pedagógico universitário é indissociável das questões relativas à formação pedagógica do docente do ensino superior. De tal modo, é preciso questionarmo-nos de que formação se está falando? Ascender à docência universitária muitas vezes significa ocupar um cargo por decorrência de se ter alcançado o máximo da formação especializada em determinada área de conhecimento; normalmente, o profissional de determinada área já possui todos os níveis e graus de formação, mas não teve contato com os saberes da profissão docente. Com isso, a questão que se coloca é se o docente universitário se formou para o exercício da docência ou para a atividade da pesquisa.

A docência universitária, por vezes, é requerida ao profissional que adentra a universidade após uma seleção, que, apesar de exigir dele uma prova didática, analisa realmente seu currículo, na busca da verificação quantitativa das publicações que possui, no atual sistema político-acadêmico de divulgação científica em periódicos. Apesar de avaliado por sua produção no campo da pesquisa, esse profissional se sujeita à docência porque esta atividade faz parte de seu contrato; seu desejo, no entanto, muitas vezes, se concentra na perspectiva de ser um importante pesquisador. Corrobora a isso o fato de os critérios avaliativos utilizados pelo próprio sistema das universidades colocarem ênfase na produtividade do trabalho do docente-pesquisador, em virtude de suas pesquisas. $\mathrm{O}$ que se realiza como docente pouco é mencionado, ou valorizado. Assim, a docência se reduz a mais uma atividade daquele profissional dentro da universidade, uma atividade com menos valor que outras.

Nesse cenário, Carrasco (2016), em sua pesquisa de Mestrado, buscou verificar quais as concepções de formação que estão presentes nos espaços de formação pedagógica do docente universitário que existem institucionalmente em universidades públicas do estado de São Paulo. Na referida pesquisa voltou o olhar para o assessor pedagógico ou formador, isto é, aquele profissional que se dedica a propor reflexões sobre as questões da docência aos professores. No caso das universidades pesquisadas, eram docentes da própria universidade, de diversas áreas, não só dos setores da Pedagogia ou da Educação, a realizar este trabalho de formação pedagógica. Nos casos pesquisados, todos com respaldo institucional.

Carrasco (2016) verificou, assim, com sua pesquisa bibliográfica e de campo, que há inúmeras dificuldades para que o professor universitário se veja como docente e deseje se formar como tal. Verificou, ainda, que os desafios do assessor pedagógico são inúmeros para que possa desenvolver um trabalho coerente, emancipatório, de continuidade junto aos docentes. Constatou que a assessoria pedagógica ao docente universitário ainda se caracteriza como uma carreira em construção no Brasil, mesmo que muitas iniciativas no sentido de aprofundamento e concretização desta função existam há tempos em muitas universidades.

Pensar este ator, que em muitas universidades atua na formação continuada do docente, não é tarefa fácil pois a função está em construção e o que se vê é uma variedade de possibilidades, tanto no modelo das formações, como na constituição do papel do assessor pedagógico e dos espaços de formação. O próprio termo não é utilizado de forma unânime, pois muitos dos responsáveis por centros de formação continuada do docente, em diversas universidades, não se veem como assessores pedagógicos.

Cunha (2014) aponta que, no Brasil, essa ação de assessoria normalmente era realizada por docentes, titulares das universidades, que eram da área pedagógica. Apesar da legitimação que essa situação traz à formação, há relatos de que "sua permanência na ação assessora é transitória, pois o vínculo funcional que possuem não as compromete prioritariamente com esse espaço de atuação" (Cunha, 2014).

Mais recentemente, segundo a autora, as Instituições de Ensino Superior (IES) têm realizado concurso público para admitir "pedagogos ou técnicos em assuntos educacionais para suprir a necessidade das assessorias pedagógicas" (Cunha, 2014), o que apresenta pontos positivos. No entanto, pela natureza do curso de Pedagogia e pela falta de experiência desses profissionais com o ensino universitário, as dificuldades podem ser muito grandes no exercício de sua função junto aos demais docentes, de modo que "o fato é que as IES têm, também, de investir na qualificação dos assessores, favorecendo seu próprio desenvolvimento profissional" (Cunha, 2014).

Pimenta e Almeida (2011) mencionam as iniciativas de formação continuada de docentes universitários nas universidades da Espanha. Observaram que todas as universidades da Espanha contam com essas iniciativas de formação e que os professores aderem a esta formação de maneira voluntária. Cunha (2014) afirma que, por sua vez, a Argentina já está numa fase mais amadurecida deste processo. As iniciativas de Lucarelli (2004), Mallet (2010), Mayor Ruiz (2007), que buscaram avançar nos estudos sobre assessoria pedagógica, têm criado uma cultura de valorização desta função, tornando-se referência no campo da Pedagogia Universitária.

Pimenta e Almeida (2011) veem a característica da formação espanhola como algo muito próximo do que acontece no Brasil. Muitas universidades possuem algum tipo de iniciativa de formação pedagógica e a adesão é voluntária. A maior aproximação do quadro brasileiro ao 
espanhol é com relação ao desafio de fazer com que essa formação chegue à "massa de professores que não sente necessidade de se aperfeiçoar profissionalmente para a ação de ensinar" (Pimenta \& Almeida, 2011). Por outro lado, Cunha (2014) coloca que no Brasil as experiências de formação pedagógica nas universidades, apesar de existirem, "são pontuais e dependentes da sensibilidade dos gestores universitários que ora implementam equipes e programas nesse sentido, ora desativam essas estruturas". Essa realidade, segundo autora, torna raras as iniciativas que sobrevivem a esses desafios e se consolidam dentro da instituição. Com relação ao assessor pedagógico, na situação dessas iniciativas no Brasil, normalmente tem pouco reconhecimento acadêmico, tornando "incipientes as condições de estruturação das equipes assessoras" (Cunha, 2014).

Por haver tantos desafios ainda para que se possa legitimar o campo de atuação do assessor pedagógico é que este estudo se configura em válida reflexão para que se possa engendrar uma transformação nos modos de ver e pensar a docência universitária. Logo, se o objetivo é compreender melhor essa profissão que se ocupa de planejar e desenvolver ações junto aos docentes, com vistas a mediar seus processos de desenvolvimento profissional (Xavier, 2014), para iniciar, é interessante lançar algumas questões que orientam nosso percurso teórico: Quem é o assessor pedagógico dentro da universidade? Por que é importante que ele exista nesse contexto? Onde atua? Como atua? Qual o papel, afinal, desse ator dentro desta instituição e, especialmente, dentro destes espaços de formação? Qual seu papel junto ao docente?

\section{Buscas de uma descoberta: qual o papel do assessor pedagógico na universidade?}

Elisa Lucarelli, docente na Universidade de Buenos Aires (UBA), estuda o tema do assessoramento pedagógico há algum tempo e tem pesquisas importantes acerca do assessor pedagógico dentro das universidades. Apesar de, inicialmente, parecer que aqui se irá falar de uma realidade estrangeira, diferente da brasileira e totalmente descontextualizada, o inverso pode ser observado, pois a referida autora tem parceria com as reflexões acerca da assessoria pedagógica também no Brasil, especialmente com Maria Isabel da Cunha, com quem sempre está realizando pesquisas que cruzam as realidades dos dois países. Assim, a visão da autora é bastante pertinente para o presente estudo.

Lucarelli (2004) reúne os resultados de pesquisas realizadas por seu grupo de estudos e pesquisas na década de 1990, quando já se pensava nas questões da formação do docente universitário e nas possibilidades de uma formação contínua. Sua obra "El assessor pedagógico en la universidad: de la teoria pedagógica a la práctica en la formación" foi escolhida por ser referência para aqueles que pesquisam a figura do assessor pedagógico. E o que se pretendia com este trabalho pioneiro? Segundo a autora, o grupo criado em 1985, no Instituto de Investigação em Ciência e Educação da Faculdade de Filosofia e Letras da Universidade de Buenos Aires (UBA), sob a direção da professora Maria Teresa Sirvent, tinha como objetivo "desenvolver um trabalho de alto nível científico, comprometido com a realidade social, política e econômica do nosso país... [como] aporte no caminho de diminuir o hiato existente entre o trabalho científico e a prática educativa" (Sirvent, 1985, citado por Lucarelli, 2004). Esta iniciativa fez parte de um projeto mais amplo da universidade que consistia na normalização da instituição pós-ditadura.

Os docentes da UBA foram convocados naquele momento para desenvolver oficinas de reflexão para a concretização da reforma curricular. Após esse primeiro período, as oficinas foram sendo reformuladas para refletir sobre as experiências inovadoras que aconteciam em toda a universidade. Os potenciais assessores pedagógicos, que emergiram do corpo docente da própria universidade, ainda se constituíam em atores estranhos ao espaço. Lucarelli (2004) afirma que, muitas vezes, esses profissionais se sentiam estrangeiros em territórios acadêmicos de outras profissões, especialmente quando eram da área da educação, da Pedagogia.

Assim, em 1989, o grupo pensou na possibilidade de "organizar encontros que se referissem especificamente à problemática do assessor pedagógico universitário" (Lucarelli, 2004). Esses encontros aconteceram no intuito de verificar a situação dos profissionais que estavam atuando na UBA como assessores pedagógicos, conhecendo a organização do trabalho deles para poder elaborar propostas de trabalho e para regularização de sua situação como assessores, que estavam apenas designados e não interinamente nos cargos, com algumas exceções.

Lucarelli (2004) diz que as discussões provenientes desses encontros foram levantando novos pontos de discussão sobre essa função, mas a questão que se colocou como problema de pesquisa foi sobre "qual é o papel do assessor pedagógico na universidade?". Esta questão gerou, em 1995, um grande movimento de investigação que se intitulou: "A construção do papel da assessoria pedagógica e a inovação na cátedra universitária".

A pesquisa foi realizada entre os anos de 1995 e 1996, contando com 38 participantes, docentes das diversas áreas e disciplinas da UBA e de outras universidades, públicas e privadas. A investigação se deu por meio de 
um curso que foi oferecido aos assessores pedagógicos e que se chamava "Paradoxos de um papel: o assessor pedagógico na universidade". A metodologia utilizada foi a pesquisa participativa, gerada no campo das ciências sociais em sua vertente crítica. Este tipo de investigação exige a participação real dos envolvidos na pesquisa e não apenas simbólica. $\mathrm{O}$ fato de a formação ter sido oferecida em serviço facilitou a coleta e análise dos dados, pois nesta proposta de trabalho é fundamental que aconteça a "articulação teoria e prática entendida numa perspectiva dialética acerca do conhecimento" (Sirvent, 1994, citado por Lucarelli, 2004).

Importante ressaltar que os grupos que participaram da investigação foram bastante heterogêneos no que diz respeito a profissionais e disciplinas. Havia graduados nas Ciências e na Educação; havia assessores pedagógicos, docentes da graduação e da pós-graduação. Essa composição acena com o fato de haver no grupo "distintos olhares e distintas abordagens acerca de um mesmo objeto de indagação" (Lucarelli, 2004), além das diferentes formações pessoais e profissionais que contribuíram para esses diferentes olhares. Lucarelli (2004) afirma, assim, que o referido curso cumpriu com seu objetivo geral, que era "refletir sobre as características do papel do assessor pedagógico na instituição universitária" (Lucarelli, 2004).

Os dados obtidos com o grupo que participou da formação resultaram no referido livro organizado por Elisa Lucarelli. Cada capítulo traz um olhar sobre a assessoria pedagógica universitária, que vem demonstrar as dificuldades dessa função, seus desafios, mas também, grandes possibilidades de intervenção. As análises foram iniciadas com o olhar voltado à didática universitária. Neste capítulo, escrito pela própria Lucarelli (2004), os encaminhamentos se dão no sentido de perceber, entre outras coisas, que os assessores pedagógicos, "como atores dinamizadores das práticas que acontecem na aula universitária" (Lucarelli, 2004), auxiliam na legitimação dessa didática.

O melhoramento da qualidade dos processos de ensino e de aprendizagem está ligado à reflexão entre teoria e prática e isso depende de ações desencadeadoras de processos formativos fundamentais para que existam mudanças efetivas na forma de se ver a didática universitária. Nesse sentido, durante toda a pesquisa, foi verificado que os assessores participantes se colocaram como os atores que podem desencadear essas reflexões, que podem estimulá-las em um trabalho conjunto com os docentes. Não um trabalho onde o assessor é alguém que sabe mais e melhor do que o docente, mas onde ambos têm a contribuir com o processo e realizam um trabalho em conjunto.

Com relação ao papel do assessor pedagógico na universidade, Martha Nepomneschi (2004), que escreve o segundo capítulo do livro, evidencia que os participantes da formação realizavam ações de registro e ações de intervenção. Algumas dessas questões foram feitas no início do seminário e outras ao final. Além dessas ações, os participantes descreviam a experiência de trabalho, que acontecia dentro de uma mesma instituição, ou seja, havia, em suas ações, uma base normativa comum.

A partir desses dados a autora faz diversas reflexões sobre o papel do assessor pedagógico. Primeiramente, traz a reflexão de que, apesar da formação docente estar em alta em todos os níveis educacionais, a formação do docente universitário gera sempre muita polêmica, pois ainda há a crença de uma formação dentro de uma orientação teórica, o que causa um distanciamento entre teoria e prática. Mesmo com o desenvolvimento de uma cultura de formação pedagógica dentro das universidades, pois em muitas delas há um profissional destinado a orientar os professores nas questões pedagógicas, que ajuda a refletir sobre a prática docente, ainda é muito difícil a aceitação de muitos docentes com relação a este profissional. Nepomneschi (2004) diz que antes de falar propriamente do papel do assessor pedagógico é necessário contextualizar essa realidade na universidade.

O contexto sociocultural que rodeia tudo o que é relacionado ao trabalho acadêmico, a produção do conhecimento, as atitudes acerca da aprendizagem, as representações sociais sobre o saber e o fazer e a hegemonia do modelo neoliberal, contaminam com força os espaços institucionais e deixam uma escassa margem para uma visão otimista sobre o presente e futuro da educação, na visão tanto dos docentes, como dos alunos, como com a seriedade e preocupação que o tema merece (Nepomneschi, 2004, p. 56).

A realidade que se coloca na universidade, seu contexto com relação ao modelo neoliberal, capitalista, voltado ao mercado, acaba reforçando a pouca reflexão, a instrumentalização e isso interfere nas concepções de ensino e de aprendizagem do docente universitário. É possível transformar esses aspectos por meio da formação pedagógica, mas, para tanto, a formação ainda tem muito a caminhar para poder realmente transformar essa realidade. A pesquisa de Lucarelli, que foi realizada há 20 anos, já apontava este contexto que se mantém, resiste e persiste até os dias de hoje.

Sobre o papel do assessor, a autora destaca algumas questões que surgiram a partir das respostas às perguntas realizadas e aos relatos dos assessores no decorrer da formação. Uma delas é de que o assessor 
carrega uma "multiplicidade de demandas indiscriminadas" (Nepomneschi, 2004), ou seja, realiza muitas tarefas e nem todas seriam realmente parte de seu trabalho. Outra questão é que a demanda de mudança nas práticas é tão grande quanto os limites institucionais para poder chegar até elas. Muitos depoimentos mostram que o sentimento do assessor pedagógico com relação ao seu papel é de solidão, impotência e isolamento. São muitas frentes de trabalho e nenhuma delas ainda legitima o trabalho do assessor. Essa é uma questão clara na pesquisa de Lucarelli (2004) e na pesquisa de Carrasco (2016). Por vezes os assessores são procurados apenas para darem orientações técnicas relativas à elaboração de planos, propostas de avaliações institucionais e outras demandas da gestão que não fazem jus aos espaços de discussão, reflexão e intercâmbio que pretendem ocupar.

De forma geral, o que os participantes acreditam que sejam parte de sua tarefa são as questões colocadas por eles mesmos durante a formação, que foram agrupadas em temas convergentes, sendo eles, "1. assessoramento para professores titulares; 2. facilitar a comunicação e o assessoramento e 3. desenvolvimento de projetos inovadores e de investigação educativa" (Nepomneschi, 2004). Nesses três agrupamentos o assessor pedagógico tem uma multiplicidade de papeis que lhe são atribuídos, dentro dos aspectos emocional, de mediador e de desencadeador de inovações. Nesse sentido, afirma-se que a figura do assessor aparece com uma pluralidade de tarefas, onde fica difícil identificar realmente seu papel formador em meio a tantos papeis que a ele são atribuídos.

Em se tratando de um papel em construção, é fundamental que outros espaços de reflexão surjam e que os existentes se fortaleçam para que se pense nessa importante função, pois, definir o papel do assessor pedagógico na universidade é primordial para que seu trabalho floresça junto aos docentes e à realidade que assola a instituição. Hevia (2004), dentro do mesmo estudo, traz a reflexão sobre a complexidade da construção profissional do assessor em virtude da variedade de atores com os quais têm de lidar, além da heterogeneidade de exigências, especialmente relacionadas às questões institucionais.

Assim, a função formativa do assessor pedagógico aparece repleta de desafios, que necessitam ser superados. Um dos desafios a serem superados, segundo a autora, é o caráter instrumental que pode tomar conta da função do assessor pedagógico, pois, os depoimentos dos profissionais participantes daquela pesquisa mostram que os resultados esperados da atuação do assessor pedagógico acabam tomando um rumo imediatista, sendo cobradas mudanças nas práticas educativas dos docentes que passam pelas formações e resultados nas aprendizagens dos estudantes. Assim, a questão da formação passa a ser medida em termos de quantidade, o que imprime um caráter instrumentalista à função.

Neste sentido, sendo a docência uma profissão complexa, mudanças superficiais pouco refletem nas questões que realmente podem ser foco do desejo de transformação. Por isso, requer-se o cuidado com o papel do assessor para que ele não caia na armadilha de querer ter quantidade em detrimento da qualidade, efetivando a formação desvinculada de concepções bem fundamentadas que se convertem em nada mais que treinamento. Não seria assim concebida a formação do docente universitário na linha em que se engendra este estudo.

Deste modo, Hevia (2004) levanta a questão de que é necessário verificar as concepções que permeiam os processos formativos. Ela levantou, por meio de vários autores, concepções de processos formativos, do papel atribuído ao docente, e concepções voltadas à instituição onde essas formações acontecem. A autora afirma que "o exame realizado acerca das ações do assessor pedagógico, em seu desempenho, se enumera numa grande variedade de modalidades e dispositivos destinados à formação do docente universitário" (Hevia, 2004). Isso significa que seu papel formativo é o que se tem de fundamental em sua atuação de assessor pedagógico.

\section{Os Núcleos de Formação Pedagógica em questão}

No Brasil há um grupo de pesquisadores também interessado em aprofundar as discussões sobre a formação pedagógica do docente universitário.

Entre os estudos encontrados está o da professora Graziela Pachane, de 2003, intitulado de: "A importância da formação pedagógica para o professor universitário", um estudo feito para refletir a formação do docente universitário a partir do estágio docência, estudo realizado na Universidade de Campinas (UNICAMP); outra pesquisa foi a de Cecília Luiza Broilo, em 2004, que analisa a formação do docente universitário em três contextos diferentes, a Universidade do Vale do Rio do Sinos (UNISINOS), na Universidad de La Republica de Uruguay (UNIDELAR), de Montevidéu - Uruguai e na Universidade de Aveiro (UA), em Portugal; uma pesquisa totalmente voltada aos centros de formação estabelecidos nessas universidades. A pesquisa de Meirecele Caliope Leitinho (2007), que em seu trabalho procura identificar as iniciativas em duas universidades do Ceará, reflete sobre a formação dos docentes nesses espaços. Cássia Ferri (2009) estudou especificamente o programa de formação continuada da Universidade do Itajaí e Souza (2010), ao 
fazer um levantamento sobre essas pesquisas, define que a temática da formação do docente universitário tem sido o foco de mais pesquisas do que já houve em qualquer momento. Entretanto, afirma também que a figura do assessor pedagógico e os Centros de Formação onde esses assessores atuam ainda é tema pouco explorado. Neste levantamento que Souza (2010) faz nada aparece acerca do assessor pedagógico. Fala-se nas iniciativas de formação pedagógica, sua constituição, atuação, desafios e conquistas, mas com pouco foco naqueles que se mobilizam para fazer acontecer esses espaços.

Justifica-se, portanto, pelo próprio levantamento bibliográfico, a importância de se pensar este ator, ainda tão desconhecido de todos, inclusive na nomeação de sua função: assessor, formador, pedagogo, técnico de assuntos educacionais, confundindo-se cargo com a função de assessoramento. Sua construção identitária ainda é frágil e precisa ser fortalecida e, um dos caminhos vistos para que isso ocorra é a pesquisa, bem como a divulgação desta, que pode ajudar na transformação da realidade deste profissional ainda sem pátria, estrangeiro em todos os territórios que busca atuar.

\section{Achados mais recentes: antigas constatações, muitas possibilidades}

Com publicação no ano de 2014, o Grupo de Pesquisa, Ensino, Formação de Professores e Avaliação, do Programa de Pós-graduação em Educação da Universidade do Vale do Rio dos Sinos - UNISINOS, coordenado pela professora Maria Isabel da Cunha, realizou vários estudos sobre os espaços de formação continuada do docente universitário e sobre a figura do assessor pedagógico. Intitulado "Estratégias Institucionais para o Desenvolvimento Profissional Docente e as Assessorias Pedagógicas Universitárias", os trabalhos foram apresentados pelo grupo em forma de estudos que levantam a situação dos espaços de formação presentes em diversas universidades. O prefácio, escrito por Elisa Lucarelli, traz a satisfação desta autora em escrever sobre obra de tamanho valor, que reúne estudos essencialmente relevantes de aprofundamento e compreensão da formação do docente universitário e do assessoramento pedagógico na universidade.

Lucarelli diz que investigações como esta, organizada por Maria Isabel da Cunha, possibilitam que a função do assessor pedagógico seja vista e que seu papel possa ir se definindo, trazendo a importância de seu trabalho, as possibilidades de intervenção e a "construção de uma teoria pedagógica e didática específica do nível superior" (Cunha, 2014). Dez estudos compõem o livro e o primeiro, escrito pela organizadora, Maria Isabel da Cunha, traz um aprofundamento teórico, que oferece um subsídio comum para a análise dos dados dos demais estudos.

Cunha (2014) inicia o texto rememorando assuntos já discutidos em outros estudos de sua autoria sobre a questão da formação do docente universitário, sobre a concepção de formação, sobre os espaços, lugares e territórios de formação deste docente dentro de seu ambiente de trabalho. Após retomar o assunto e suscitar outras reflexões sobre essas temáticas, traz um "referencial de análise de experiências de formação docente" (Cunha, 2014). Nesse referencial, Cunha (2014, p. 39-42) apresenta-nos três modelos de formação docente: $\mathrm{O}$ modelo de "Centralização e Controle das Ações" (A); modelo "Parcial de Descentralização e Controle das Ações" (B) e modelo "Descentralizado de Acompanhamento e Controle das Ações" (C). A autora utilizou esses modelos para analisar o assessoramento pedagógico por vários ângulos, a fim de promover a compreensão do trabalho deste importante ator na formação continuada do docente universitário. Os ângulos de análise empreitados foram os "Pressupostos e Características dos Indicadores, a Compreensão da Formação e do Desenvolvimento Profissional, os Formatos Usuais das Estratégias de Formação e os Formatos de Acompanhamento e Avaliação" (Cunha, 2014).

O modelo (A) se relaciona aos Centros de Formação que trazem uma perspectiva geral e oferecem formação a todos os docentes, as propostas são episódicas e os resultados não são controlados. Este modelo vê a docência como ação individual. O órgão gestor escolhe os temas a serem oferecidos aos docentes, há pouca escuta daqueles que participam e a avaliação é formal, feita por meio de indicadores de presença e controle de ações.

No modelo (B) os processos de formação são diversificados e são oferecidos com a preocupação de atender aos interesses e necessidades dos atores envolvidos. O planejamento atende a uma localização temporal e há algumas ações de acompanhamento. Traz propostas que envolvem a teoria e a pratica "reconhece que os professores são portadores de saberes e é sobre eles que o desenvolvimento profissional se alicerça" (Cunha, 2014). Organiza equipes de acordo com as demandas de formação. A avaliação toma como referência os objetivos que haviam sido traçados; tem a prática do registro e busca fazer um acompanhamento por meio de pesquisas.

No modelo (C) os processos de formação são desencadeados pelos próprios participantes, "o assessor atua como coadjuvante" (Cunha, 2014), o acompanhamento é feito a partir de formas autogestionárias. "Envolve mobilização interna e autogestão dos processos vividos" (Cunha, 
2014). O ponto forte é a mobilização dos docentes para a realização dos projetos acadêmicos ou políticos. As estratégias estão ligadas às demandas do grupo. A avaliação e o acompanhamento também são iniciativas que emergem do grupo.

Esses modelos foram sendo criados ao longo de um trabalho minucioso de pesquisa e retratam as possibilidades de formação que existem nos centros, núcleos, propostas de formação continuada nas universidades. A partir desses modelos é possível refletir sobre a formação oferecida em cada espaço, os caminhos que têm sido percorridos e os que ainda deverão ser traçados.

Cunha (2014) afirma que essa reflexão se une a outra essencial para se pensar nessas iniciativas de formação: a reflexão sobre os Projetos Pedagógicos das IES, pois, no Brasil, essas experiências têm sido pontuais e a maioria não está garantida pela instituição, ou seja, fica à mercê dos grupos gestores que constituem e dissolvem essas iniciativas de acordo com seus interesses, não sendo um projeto da instituição, mas de alguns grupos apenas. "São raras as experiências duradouras e consolidadas" (Cunha, 2014), como mencionado no início deste capítulo.

A autora traz a reflexão sobre a desvalorização do ensino e a valorização exacerbada da pesquisa e propõe que a pesquisa acompanhe a ação assessora, pois é uma forma de "legitimidade do saber pedagógico e da ação do assessor" (Cunha, 2014).

Em geral procura-se criar espaços de reflexão para melhorar a qualidade dos processos de ensinar e aprender; inspirar e sistematizar inovações; favorecer ações coletivas e aprendizagens com significado para todos os envolvidos. A adjetivação clínica não deve ser compreendida numa dimensão patológica, de remediar apenas conflitos, em que pese podem eles ser motivo de solicitação de apoio. A perspectiva é de uma assessoria que esteja aberta ao diálogo e disponivel para tratar de temas de interesses dos coletivos, ainda que esses possam ter encaminhamentos individuais (Cunha, 2014, p. 51-52).

Os estudos seguintes, descritos no livro pelos diversos membros do grupo de pesquisa, trataram de explanar as investigações realizadas sobre as experiências de formação continuada do docente universitário em vários espaços. Partindo de diversas metodologias, todas elas numa perspectiva qualitativa, cada uma foi encaminhada de uma forma específica, o que deu um tom muito especial a cada estudo realizado e nesta obra descrito. As universidades pesquisadas eram todas públicas ou comunitárias. Das públicas, algumas eram federais, outras estaduais.
Entre os resultados apresentados há muitos indícios que remetem a reflexões essenciais para aqueles que desejam aprofundar os conhecimentos nas questões da docência na universidade e de sua formação. Quando se propõe formação continuada ao docente, o que se busca, explicitamente, são caminhos para um ensino de qualidade, no entanto, as motivações para se buscar isso podem ser as mais variadas.

No Brasil, com o aparecimento das provas externas, na década de 1990, muitas universidades começaram a ter indicações de fragilidades em seus cursos e viram a necessidade de se buscar caminhos para atingir esse problema. Muitas iniciativas de formação continuada do docente surgiram nesse contexto. Os estudos desenvolvidos por este grupo de pesquisa, além de levantarem o que existe hoje, fazem uma retomada histórica de como surgiram algumas dessas iniciativas e como foram se constituindo, muitas delas se consolidando e se tornando trabalhos essenciais dentro das universidades pesquisadas.

Compreender como se desenvolvem essas iniciativas formativas dentro da universidade pública é outro mote das pesquisas realizadas. Compreender a importância do coletivo e a maneira como se constroem as possibilidades de reflexão entre os pares foram situações de investigação realizadas pelos grupos, explicando em cada texto os caminhos da investigação empreitados. As investigações apontaram, por vezes, que os desafios de se manter e consolidar iniciativas de formação são inúmeros, entre eles, articular o conhecimento pedagógico com os conhecimentos específicos das diferentes áreas. Outro grande desafio é o trabalho de convencimento ao docente universitário que ele precisa se formar nesse aspecto do campo pedagógico.

Alguns resultados apresentados mostraram que, a partir da existência dessas iniciativas, docentes que não conheciam os pressupostos teóricos próprios da Pedagogia Universitária puderam passar a conhecê-los e a reconhecer que necessitam de formação no aspecto pedagógico. Contudo, as pesquisas demonstraram também que a maneira como a formação é oferecida acaba sendo basilar na receptividade do docente. Dependendo da proposta que se apresente e do formato, o docente acolhe $\mathrm{e}$ permanece participando das iniciativas, e, dependendo, suas afirmações anteriores, referentes à não necessidade desse tipo de formação, confirmam-se e ele perde o interesse em buscar conhecimentos nessa área. Assim, as concepções que permearão a formação serão essenciais nesse processo de construção de confiança entre o docente, os assessores pedagógicos e os demais atores que estiverem participando, na medida em que o processo formativo for se desenvolvendo. 
Alguns estudos trouxeram o crescimento das iniciativas de formação, que começaram de forma tímida, com ideias pontuais, trabalhos específicos e foram aumentando seu grau de atuação, conquistando um espaço institucional, mudando concepções. Por outro lado, muitas iniciativas agem em várias frentes e acabam atuando não apenas como apoio didático-pedagógico, mas como mediadores entre as diferentes instâncias da universidade. Com relação às propostas de trabalho existentes nas iniciativas pesquisadas, algumas ainda trazem uma proposta mais tecnocrática e fragmentada, mas se percebe um avanço que as têm levado a se voltar para práticas de reflexão.

Uma das descobertas, realizada em um dos estudos é que "é fundamental que as instituições e os sujeitos envolvidos estejam implicados, assumindo a formação docente como valor" (Citolin et al., 2014).

Frente às múltiplas demandas e à complexidade do papel da universidade, reafirmamos a importância das assessorias pedagógicas e das estratégias por elas desenvolvidas, com vistas à instrumentalização à docência, ao planejamento coletivo, às discussões por áreas do conhecimento ou para mudança el ou reiteração do perfil e valores institucionais. Indiferentemente do modelo de controle de acompanhamento das ações desenvolvidas, as assessorias detêm a difícil tarefa de construir caminhos de formação num ambiente composto por docentes de distintas áreas, orientados por visões múltiplas e com especificas trajetórias pessoais (Citolin et al., 2014, p. 183).

Muitas iniciativas investiram na formação dos docentes ingressantes, já que estes vêm para a universidade sem preparo algum à docência, pois, como já foi visto, os mestrados e doutorados são voltados quase que exclusivamente para a formação do pesquisador e não do docente. Assim, o professor ingressante pode se interessar mais em realizar uma formação que trará subsídios para que ele assuma as aulas de forma mais efetiva.

As atividades de acolhimento e apoio aos professores podem tornar-se espaços férteis para repensar, discutir e refletir sobre os conceitos e ideias que irão auxiliar os docentes na construção de diferentes metodologias que atendam variadas situações que os professores iniciantes irão enfrentar (Zanchete et al., 2014, p. 2017).

Parece-nos importante ressaltar, no entanto, que as iniciativas de formação não deveriam se firmar em um ou em outro aspecto relativo ao ingresso, mas, procurar abranger as necessidades de todos os docentes que desenvolvem seu trabalho de ensino, pesquisa e extensão na instituição, independentemente de ser ingressante, ou de já estar na universidade há muito tempo, pois, o fato de atuar como docente há muito tempo não garante que compreenda as especificidades do ensino.

A formação continuada do docente universitário não se dá no vazio, pertence à esfera do vivido e do agido devendo ser contextualizada e reconfigurada a cada momento e em cada espaço, pelos envolvidos no processo, direta ou indiretamente. Como tal, há que compreender a complexidade, as incertezas e as ambiguidades do aprender a ser professor, tendo presente que aprendemos muito daquilo que somos e somos muito daquilo que aprendemos (Volpato, Sousa, Medeiros, \& Silveira, 2014, p. 244).

Ademais, a aprendizagem acontece durante toda a vida; por esse motivo, as iniciativas que se dedicam mais à formação do docente ingressante têm seu valor mas deixam de atuar em outras frentes tão importantes quanto esta.

Cunha (2014) apresenta muitas considerações ao finalizar o livro sobre os achados de tão relevante pesquisa, entre eles a reflexão sobre o papel dos assessores pedagógicos. Na maioria das iniciativas essa função foi assumida por docentes ligados à área pedagógica das universidades; no entanto, "os relatos mostraram que sua permanência na ação assessora é transitória, pois o vínculo funcional que possuem não os compromete prioritariamente com esse espaço de atuação" (Cunha, 2014). Assim, Cunha (2014) afirma, mais uma vez, que as IES precisam investir, também na "qualificação dos assessores, favorecendo o seu próprio desenvolvimento profissional", para poder, assim, qualificar a formação que se pretende desenvolver junto aos docentes.

\section{Os conceitos de assessoramento pedagógico em questão}

Como já mencionado, a Argentina já tem uma caminhada de estudos na área da assessoria pedagógica e isso faz com que aconteçam eventos voltados para a temática, que promovem a divulgação das pesquisas que estão sendo realizadas no campo da formação pedagógica.

Em setembro de 2015 aconteceu o "IV Encuentro Nacional y I Latinoamericano de Prácticas de Asesorías Pedagógicas Universitárias (APU): hacia la búsqueda de su identidade y legitimación institucional", na Universidad Nacional de Tucumán, Argentina. Em setembro de 2017 aconteceu o "V Encuentro Nacional y II Latinoamericano 
de Prácticas de Asesorías Pedagógicas Universitárias (APU): conversasiones urgentes y nuevos desafios em contextos complejos". Um dos objetivos desses encontros foi "favorecer um espaço de socialização e intercâmbio de experiências em práticas de assessoramento pedagógico universitário" (Villagra, 2015), além de pretender contribuir nos avanços da reflexão sobre o papel do assessor pedagógico na universidade.

Além das presenças das professoras Elisa Lucarelli e Maria Isabel da Cunha, pesquisadoras com ascensão no campo, os encontros contaram com a divulgação de experiências de trabalhos de assessoramento pedagógico no Uruguai, Chile, Argentina, Brasil, México. Os encontros promoveram reflexões sobre a situação institucional desse ator, seu papel, sua atuação, os desafios, as dificuldades e novos horizontes para esta função. Questões relacionadas às controvérsias sobre os conceitos de assessoramento, qual o melhor formato de formação, quem deve ser o assessor pedagógico, emergiram das experiências apresentadas, o que enriqueceu a discussão. Se o assessoramento se constitui a partir de docentes da própria universidade, que dividem seu tempo em serem docentes, pesquisadores e assessores, ou se há a contratação de um profissional especificamente para realizar esta função; financiamento das iniciativas de formação; como deve acontecer; o desafio de ter uma quantidade maior de adesão a esta formação; as diversas frentes que compõem o papel do assessor; a institucionalização do assessoramento pedagógico; todos esses aspectos estiveram em pauta e as discussões foram muito ricas.

Há uma grande campanha para que as assessorias pedagógicas sejam institucionalizadas de forma que essa função não fique à mercê das gestões que vêm e vão nas universidades de toda a América Latina. Continuar com o trabalho voluntário de alguns docentes que se propõem a essa tarefa não é o bastante para mudar o cenário da formação pedagógica do docente universitário. Questões como esta foram muito discutidas nos eventos.

Elisa Lucarelli, no evento de 2015, colocou que o assessor pedagógico deve ser aquele que promove um "processo interativo de colaboração" (informação verbal), frente às reflexões relacionadas ao ensino. No entanto, por vezes, o assessor é procurado para resolver problemas imediatos e este não é o seu papel. Falou ainda sobre a importância da formação dos assessores e sobre o processo reflexivo que devem desenvolver.

$\mathrm{Na}$ busca de que o assessor pedagógico universitário construa uma identidade, os eventos trouxeram reflexões fundamentais e o conforto de saber que o tema tem sido pauta de discussão em muitos espaços. A reflexão sobre a formação pedagógica do docente universitário está tomando corpo e, assim, vai se consolidando como campo de conhecimento essencial no meio acadêmico.

\section{Considerações Finais}

Considerando o campo de atuação e a realidade que tange à docência universitária, entendemos o assessor pedagógico como ator fundamental no contexto da universidade, sendo esta um legítimo espaço de ensino e de aprendizagem. Um espaço onde se desenvolvem processos de aprendizagem reais que orientam o âmbito profissional, mas que não se limita a apenas isso; trata-se de um espaço que deve, por missão, valorizar o ser humano em todas as suas potencialidades e que, para tanto, deve permitir que todos os envolvidos, docentes e estudantes, vivenciem este processo de forma a protagonizar essa formação.

Contudo, há que se repensar o exercício profissional da docência neste espaço, pois as pesquisas realizadas no campo, que compuseram o corpo teórico aqui citado, como também outros estudos de autores que têm se debruçado sobre a docência universitária, têm mostrado que ainda hoje a docência é praticada muito mais por modelos, normalmente fundamentados na concepção do ensino como transmissão do conhecimento, e não pela construção de saberes mútuos, dentro de uma relação que deve se estabelecer entre docente e estudante, nos processos de ensinar e de aprender. Assim, a profissão docente universitário, normalmente, é construída pela experiência do professor em sua vida escolar e acadêmica.

Assim, para ter condições de efetivamente se constituir enquanto docente, é necessário despertar para o fato de que são necessários saberes específicos para o exercício desta profissão. Para tanto, o docente universitário, vindo das diversas áreas do conhecimento, necessita se formar pedagogicamente, em diálogo com seus pares e com profissionais que possam impulsionar a construção dos saberes específicos da docência. Este profissional é o assessor pedagógico, profissão em construção que ainda não possui a legitimidade devida, como formador suficiente, na maioria dos locais em que atua.

Assim percebida a realidade que orienta a construção desta profissionalidade do assessor pedagógico, entendemos necessário também que tais profissionais se assumam como formador de formadores, admitindo, para tanto, que necessitam de conduzirem processos de autoformação, com fomento institucional, porque estes também auxiliam na legitimidade do trabalho desenvolvido. Estas são questões nos parecem essenciais para que sua atuação seja capaz de transformar a realidade posta hoje no campo do ensino das universidades do Brasil. 


\section{Referências}

Broilo, C. L. (2004). Assessoria Pedagógica na Universidade: (Con)formando o trabalho docente. Araraquara, SP: Junqueira \& Marin.

Carrasco, L. B. Z. (2016) Assessorias pedagógicas das universidades estaduais paulistas: concepções dos espaços institucionais de formação do docente universitário. (Dissertação de Mestrado em Educação). Instituto de Biociências - UNESP, Rio Claro, SP. Recuperado de https://repositorio.unesp.br/handle/11449/139533

Citolin, C. B., Ramos, I. V., Salami, M. C., Forster, M. M. S., Reschke, M. J. D., Pinto, M. M., ... Costa, V. B. (2014). Estratégias institucionais para o desenvolvimento profissional docente em IES comunitárias gaúchas: trajetórias e desafios. In: Cunha, M. I. (Org.) Estratégias institucionais para o desenvolvimento profissional docente e as assessorias pedagógicas universitárias: memórias, experiências, desafios e possibilidades. Araraquara, SP: Junqueira \& Marin.

Cunha, M. I. (Org.) (2014). Estratégias institucionais para o desenvolvimento profissional docente e as assessorias pedagógicas universitárias: memórias, experiências, desafios e possibilidades. Araraquara, SP: Junqueira \& Marin.

Ferri, C. (2009). Formação continuada de professores universitários: a experiência da universidade do Vale do Itajaí. In. Isaia, S. M. A., \& Boltan, D. P. V. (Org.). Pedagogia universitária e desenvolvimento profissional docente. Santa Maria, RS: EDIPUCRS, p. 267-280.

Hevia, I. A. (2004). El assessor pedagógico em la formación del docente universitário. In. Lucarelli, E. (Org.). El asesor pedagógico em la universidad: de la teoria a la práctica en la formación. Buenos Aires, AR: Paidós Educador.

Isaia, S. M. A., Maciel, A. M. R., \& Bolzan, D. P. V. (2011). Pedagogia universitária: desafio da entrada na carreira docente. Educação, 36(3), 425-440.

Leitinho, M. C. (2007). A formação pedagógica do professor universitário nas universidades cearenses: um estudo de casos múltiplos. Relatório científico-acadêmico do estágio de pós-doutorado. UnB. Brasília, DF.

Lucarelli, E. (Org.). (2004). El asesor pedagógico em la universidad: de la teoria a la práctica en la formación. Buenos Aires, Argentina: Paidós Educador.

Lucarelli, E., \& Mallet, A. M. (Org.) (2010). Universidad y prácticas de innovación pedagógicas: estudio de casos en la UNS. Buenos Aires, Argentina: Jorge Baudino Ediciones.

Mayor Ruiz, C. (Org.). (2007). El asesoramiento pedagógico para la formación docente del professorado universitário. Sevilla: Editora Universidade de Sevilla.

Nepomneschi, M. (2004). El rol del assessor pedagógico em la universidad: la búsqueda de um lugar. In. Lucarelli, E. (Org.). El asesor pedagógico em la universidad: de la teoria a la práctica en la formación. Buenos Aires, Argentina: Paidós Educador.

Pachane, G. G. (2003). A importância da formação pedagógica para o professor universitário: experiência da Unicamp. (Tese de Doutorado em Educação). Faculdade de Educação, Universidade Estadual de Campinas, Campinas, SP. Recuperado de http://repositorio.unicamp.br/jspui/handle/REPOSIP/252864

Pimenta, S. G., \& Almeida, M. I. (Org.) (2011). Pedagogia Universitária: caminhos para a formação de professores. São Paulo, SP: Cortez.

Sirvent, M. T. (1985). Nuestra propuesta de trabajo: produto de uma tarea compartida. Serie Participación, n. 3. Buenos Aires, Argentina: UBA, FFYL.

Souza, M. E. G. (2010). Docente da educação superior e os núcleos de formação pedagógica. Tese (Doutorado em Educação). Universidade de Brasília, DF.

Villagra, M. A. (2015). Apresentação. Libro de Resúmenes do IV Encuentro Nacional y I Latinoamericano de prácticas de asesorías pedagógicas universitárias (APU). Universidad Nacional de Tucumán (UNT) - Facultad de Filosofia y Letras, Tucumán, Ar.

Volpato, G., Souza, A. R. B., Medeiros, D. R. \& Silveira, J. (2014). A formação do docente universitário em Santa Catarina: estratégias institucionais das IES comunitárias. In. Cunha, M. I. (Org.). Estratégias institucionais para o desenvolvimento profissional docente e as assessorias pedagógicas universitárias: memórias, experiências, desafios e possibilidades. Araraquara, SP: Junqueira \& Marin.

Xavier, A. R. C. (2014). Universidade Nova: desafios da prática pedagógica numa perspectiva interdisciplinar. (Dissertação de Mestrado em Educação). Instituto de Biociências - UNESP, Rio Claro, SP. Recuperado de https:// repositorio.unesp.br/handle/11449/154652 
Zanchete, B. M. B. A., Fagundes, M. C., Vighi, C. S. B., Neves, C. H. C., Lemos, H. F. R., Selbach, P. T., ... Stinvani, N. (2014). Tempos e espaços de inserção e Desenvolvimento profissional de docentes universitários iniciantes. In. Cunha, M. I. (Org.). Estratégias institucionais para o desenvolvimento profissional docente e as assessorias pedagógicas universitárias: memórias, experiências, desafios e possibilidades. Araraquara, SP: Junqueira \& Marin.

Recebido 31/01/2018

$1^{a}$ Reformulação 19/07/2018 Aceite Final 07/10/2018

Sobre as autoras

Ligia Bueno Zangali Carrasco possui graduação em Pedagogia pela UNESP - Rio Claro (2005), Mestrado em Educação (2016) e está com o Doutorado em Educação pela mesma instituição, pesquisando as assessorias pedagógicas universitárias e sua profissionalidade. Atua como diretora de escola da Rede Municipal do município de Rio Claro-SP.

Amanda Rezende Costa Xavier possui graduação em Pedagogia pelo Centro Universitário do Sul de Minas (2006), Mestre em Educação pela UNESP - Rio Claro (2014), Doutoranda em Educação pela UNESP - Rio Claro, Pedagoga na Universidade Federal de Alfenas no campus avançado de Poços de Caldas.

Maria Antonia Ramos de Azevedo, Graduação em Pedagogia pela Pontifícia Universidade católica de São Paulo, Mestrado em Educação pela Universidade Federal de Santa Maria, Doutorado em Educação pela USP-SP, Pós-doutorado em Pedagogia Universitária pela Universidade do Rio dos Sinos-RS. Atua como docente na UNESP - Rio Claro. 